Technological University Dublin

DƯBLIN

ARROW@TU Dublin

2005-01-01

\title{
Investigation of the Effect of Subcutaneous Fat on Image Quality Performance of 2D Conventional Imaging and Tissue Harmonic Imaging
}

\author{
Jacinta Browne \\ Technological University Dublin, jacinta.browne@tudublin.ie \\ Amanda Watson \\ Western Infirmary Glasgow \\ Peter Hoskins \\ University of Edinburgh
}

See next page for additional authors

Follow this and additional works at: https://arrow.tudublin.ie/scschphyart

Part of the Physics Commons

\section{Recommended Citation}

Browne, J., Watson, A., Hoskins, P., Elliott, A.: Investigation of the Effect of Subcutaneous Fat on Image Quality Performance of 2D Conventional Imaging and Tissue Harmonic Imaging. Ultrasound in Medicine and Biology, Vol. 31 (7), pp.957-964. 2005. doi:10.1016/j.ultrasmedbio.2005.03.012

This Article is brought to you for free and open access by the School of Physics \& Clinical \& Optometric Science at ARROW@TU Dublin. It has been accepted for inclusion in Articles by an authorized administrator of ARROW@TU Dublin. For more information, please contact arrow.admin@tudublin.ie, aisling.coyne@tudublin.ie, gerard.connolly@tudublin.ie.

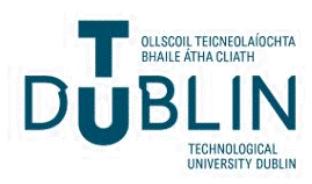


Authors

Jacinta Browne, Amanda Watson, Peter Hoskins, and Alex Elliott

This article is available at ARROW@TU Dublin: https://arrow.tudublin.ie/scschphyart/8 
INVESTIGATION OF THE EFFECT OF SUBCUTANEOUS FAT

ON IMAGE QUALITY PERFORMANCE OF 2D

CONVENTIONAL IMAGING AND TISSUE HARMONIC

IMAGING

JACINTA E BROWNE ${ }^{1}$, AMANDA J WATSON ${ }^{1}$, PETER R HOSKINS ${ }^{2}$ AND

ALEX T ELLIOTT ${ }^{1}$

Department of Clinical Physics, Western Infirmary, Glasgow, UK ${ }^{1}$

Department of Medical Physics, University of Edinburgh, $\mathrm{UK}^{2}$

Correspondence Address

Dr Jacinta E Browne,

School of Physics,

Dublin Institute of Technology,

Kevin Street,

Dublin 8,

Ireland.

Email: jacinta.browne@dit.ie

Running Title: EFFECT OF FAT LAYERS ON 2D IMAGE QUALITY 


\section{INVESTIGATION OF THE EFFECT OF SUBCUTANEOUS FAT \\ ON IMAGE QUALITY PERFORMANCE OF 2D}

CONVENTIONAL IMAGING AND TISSUE HARMONIC

\section{IMAGING}

\section{ABSTRACT}

Tissue harmonic imaging (THI) has been reported to improve contrast resolution, tissue differentiation and overall image quality in clinical examinations. However, a study carried out previously by the authors (Browne et al 2004) found improvements only in spatial resolution and not in contrast resolution or anechoic target detection. This result may have been due to the homogeneity of the phantom. Biological tissues are generally inhomogeneous and THI has been reported to improve image quality in the presence of large amounts of subcutaneous fat. The aims of the study were to simulate the distortion caused by subcutaneous fat to image quality and thus investigate further the improvements reported in anechoic target detection and contrast resolution performance with THI compared with $2 \mathrm{D}$ conventional imaging. In addition, the effect of three different types of fat-mimicking layer on image quality was examined. The abdominal transducer of two ultrasound scanners with 2D conventional imaging and THI were tested, the 4C1 (Aspen-Acuson, Siemens Company, CA, USA) and the C5-2 (ATL HDI 5000, ATL / Philips, Amsterdam, The Netherlands). An exvivo subcutaneous pig fat layer was used to replicate beam distortion and phase aberration seen clinically in the presence of subcutaneous fat. Three different types of fat-mimicking layers (olive oil, lard and lard with fish oil capsules) were evaluated. The subcutaneous pig fat layer demonstrated an improvement in anechoic target 
detection with THI compared with 2D conventional imaging, but no improvement was demonstrated in contrast resolution performance; a similar result was found in a previous study conducted by this research group (Browne et al 2004) while using this tissue-mimicking phantom without a fat layer. Similarly, while using the layers of olive oil, lard and lard with fish oil capsules, improvements due to THI were found in anechoic target detection but, again, no improvements were found for contrast resolution for any of the layer combinations. Therefore, it was felt that the lack of improvement in contrast resolution performance may be due to the test phantom design and not to whether a layer was present that caused beam distortion and phase aberrations. (E-mail: jacinta.browne@dit.ie)

Key Words: Computerised image analysis program, Tissue harmonic imaging, quality control, anechoic target detection, contrast resolution performance, fat-mimicking layer. 


\section{INTRODUCTION}

Tissue harmonic imaging is a relatively recent grey-scale ultrasound imaging mode that has been clinically reported as improving image quality (Desser and Jeffrey 2001), particularly in patients who are difficult to scan with conventional ultrasound imaging, despite improvements made to transducer technology, such as piezoelectric materials with lower acoustic impedance, which have occurred during recent decades (Claudon et al 2002). The primary cause of image degradation (noise and clutter) is the composition of the body wall, in which fat, skin layer thickness and hydration level are some of the principal causes of ultrasound beam distortion and scattering. Additionally, lateral and slice thickness side lobes and reverberation artifacts contribute to generation of image clutter. Often, image degradation occurs as the sound beam traverses the layers of fat and muscle comprising the body wall. In conventional Bmode imaging, the sound beam must pass through the body wall twice. The result of this round trip through the body wall layer and tissue of different impedance is image clutter (noise). The amount of harmonics that each slight pulse distortion generates at any given instant remains infinitesimal; the cumulative harmonic intensities increase as the pulse propagates through tissue (tissue harmonic intensity is virtually zero at the skin and increases with depth up to the point where tissue attenuation overcomes this build-up and causes them to decrease again). The amplitude of the harmonics is related to the nonlinear parameter $\mathrm{B} / \mathrm{A}$, which is an inherent characteristic of the tissue. At all depths, tissue harmonic intensity remains lower than that of the fundamental. Therefore, in the case of tissue harmonic imaging, the contribution of lateral and slice thickness side lobes and reverberation artifacts to image degradation is minimal compared with fundamental imaging, because the distorted and scattered energy is 
much weaker than the transmitted energy and therefore generates much weaker harmonics. Consequently, the main distortion and scattering caused by the skin and fat layer is at reception of the harmonic signal and not for transmission of the fundamental beam. Furthermore, it has been demonstrated that the harmonic beam profile at the transducer focal zone is narrower and its side-lobe levels are lower than those of the fundamental beam, resulting in improved lateral resolution. The second harmonic signal amplitude, used for image formation in tissue harmonic imaging, varies with the square of the amplitude of the fundamental, resulting in small regional variations in the amplitude of the fundamental translating into larger variations in the amplitude of the second harmonic. This accentuates ultrasound features such as shadowing, posterior acoustic enhancement and comet-tail artifacts, which improves lesion detection and characterisation. All of these give rise to the reported improvements in contrast resolution and lateral resolution in THI images compared with fundamental mode images (Averkiou et al 1997; Christopher 1997; Desser and Jeffrey 2001; Li and Zagzebski 2000; Tranquart et al 1999; Ward et al 1997). Despite these clinical studies being conducted to evaluate the improvements in image quality, there have been limited technical evaluations to provide quantitative information about the improvements in image quality with THI (Browne et al 2004). In a previous study, the authors of this paper investigated the imaging performance of compound imaging, tissue harmonic imaging and harmonic compound imaging compared with 2D conventional imaging (Browne et al 2004) and improvements were found for axial and lateral resolution and slice thickness, with no improvements in anechoic target detection or contrast resolution performance being detected with tissue harmonic imaging and improvements in contrast resolution and anechoic target detection with compound imaging and harmonic compound imaging. These results were not 
representative of what has been reported clinically and it was felt that the absence of improvement in anechoic target detection and contrast resolution may have been due to the homogeneous nature of the test object used. Therefore, the aims of this current study were to investigate whether greater improvements in anechoic target detection and contrast resolution image quality performance could be found with THI compared with $2 \mathrm{D}$ conventional imaging when a layer of subcutaneous pig fat was used with the test phantom. In addition, studies were carried out with a view to developing a fatmimicking layer, based on the information obtained from the use of a subcutaneous pig fat layer.

\section{METHODS}

\section{Equipment}

The ultrasound scanners used in this study were the HDI 5000 (Philips/ATL, Bothell, USA) and an Acuson Aspen (Acuson / Siemens, CA, USA), both high-end systems dedicated for general ultrasound examinations. The two curvilinear abdominal 2 - $5 \mathrm{MHz}$ transducers, $4 \mathrm{C} 1$ and $\mathrm{C} 5-2$, were used in this study. Both transducers had tissue harmonic imaging mode in addition to $2 \mathrm{D}$ conventional imaging mode which was also evaluated.

\section{Tissue- and Fat-Mimicking Phantoms}

The anechoic target detection and contrast resolution measurements were performed using the Gammex-RMI model 403GS LE (Gammex RMI, WI, USA) general purpose test object (Fig 1); the tissue-mimicking material used in the phantom was an 
evaporated-milk-based gel, with a speed of sound of $1540 \mathrm{~m} \mathrm{~s}^{-1}$ and an attenuation coefficient of $0.7 \mathrm{~dB} \mathrm{~cm}^{-1} \mathrm{MHz}^{-1}$ (Browne et al 2003).

A fresh layer of subcutaneous pig fat was obtained from a local abattoir on the morning of the study and its temperature was maintained at $37^{\circ} \mathrm{C}$ using heating bags (Cole-Parmer, UK) during its transportation to the laboratory and during the testing period. The speed of sound and attenuation of pig fat in-vivo and in-vitro at $37^{\circ} \mathrm{C}$ have been previously reported in the literature to be $1426 \mathrm{~m} \mathrm{~s}^{-1}$ and $3 \mathrm{~dB} \mathrm{~cm}^{-1}$ at $2 \mathrm{MHz}$, respectively (Gammell et al 1979; Lewin and Busk 1982). Furthermore, in this study, three "fat-mimicking materials" were used, olive oil, lard and lard with fish oil capsules embedded in it. The speed of sound and attenuation of the olive oil were found to be $1490 \mathrm{~m} \mathrm{~s}^{-1}$ and $0.87 \mathrm{~dB} \mathrm{~cm}^{-1}$ at $3 \mathrm{MHz}$, respectively, whereas, for the lard, the measured values were $1550 \mathrm{~m} \mathrm{~s}^{-1}$ and $12.6 \mathrm{~dB} \mathrm{~cm}^{-1}$ at $3 \mathrm{MHz}$, respectively. The speed of sound and attenuation measurements were determined for $22{ }^{\circ} \mathrm{C} \pm 0.5^{\circ} \mathrm{C}$ using a scanning acoustic macroscope system and the data acquisition and analysis procedures described in a previous publication (Browne et al 2003). It was initially thought that the lard would have a speed of sound between $1430 \mathrm{~m} \mathrm{~s}^{-1}-1500 \mathrm{~m} \mathrm{~s}^{-1}$, since it is a fat product; however, the lard constituents stated on its packaging included salt, which would have had the effect of increasing its speed of sound. The olive oil was chosen to represent the phase aberrations usually caused by subcutaneous fat layers in the body $\left(1430 \mathrm{~m} \mathrm{~s}^{-1}-1500 \mathrm{~m} \mathrm{~s}^{-1}\right)$, whereas the lard was chosen for both phase aberrations and its uneven structure, which distorts the ultrasound beam as it passes through it, while the fish oil capsules embedded in the lard were chosen to mimic globules of fat. 


\section{Test Protocol}

The image quality parameters measured in this study were anechoic target detection and contrast resolution.

In order to evaluate the effect of the fat layer on these image quality parameters performance of two transducers (4C1 curvilinear transducer : Acuson Aspen; and C5-2 curvilinear transducer : Philips ATL HDI 5000), the following procedure was used. Initially, a $1 \mathrm{~cm}$ layer of pig fat was coupled using ultrasonic jelly to the Gammex RMI test phantom to evaluate its effect on the image quality. Different-sized fat layers were initially used in this study - but it was found that fat layers larger than $1 \mathrm{~cm}$ were very attenuating and images of the anechoic targets at depths greater than $3 \mathrm{~cm}$ could not be obtained nor could images of the contrast targets be obtained. The temperature of the pig fat layer was maintained at $37^{\circ} \mathrm{C} \pm 1^{\circ} \mathrm{C}$ using heating bags (Cole-Parmer, UK) in order to replicate in-vivo thermal conditions. The appropriate target within the test object was imaged firstly using $2 \mathrm{D}$ conventional imaging and then using the THI mode. The image was optimised and captured using a frame grabber (VideoPort, MRT, USA) for off-line analysis using a computerised image analysis program developed by the Medical Physics Department, Nottingham City Hospital (Gibson et al 2001). A description of how the computerised image analysis program measures anechoic target detection and contrast resolution and the associated measurement uncertainties are described elsewhere (Browne et al 2004; Gibson et al 2001). All of the images captured were $700 \times 500$ [pixel] $^{2}$ with an 8-bit depth resolution. The $4 \mathrm{C} 1$ and $\mathrm{C} 5-2$ transducers were tested with the "abdominal" application settings and the optimisation procedure involved adjusting the $2 \mathrm{D}$ overall gain and the time-gain-controls, as well as choosing the appropriate number of focal zones to give the best possible image of the test phantom target under test. The position and number of focal zones were kept 
constant between 2D conventional imaging and THI. The acoustic output power settings used for the $4 \mathrm{C} 1$ and the $\mathrm{C} 5-2$ curvilinear transducers was $100 \%$ and it remained constant for both $2 \mathrm{D}$ conventional imaging and THI. The transducer was fixed in place throughout the test period of both imaging modes (2D conventional imaging and THI), using a clamp and retort stand. This was the procedure used for determining both anechoic target detection performance and contrast resolution performance for 2D conventional imaging and THI for the two curvilinear abdominal transducers.

Anechoic Target Detection This examines the scanner's ability to detect and accurately display round, negative contrast objects of various sizes at different depths within the test object. This test combines aspects of spatial and contrast resolutions into a single test, gives an indication of the scanner's ability to detect cysts and is an indirect measure of the scanner's noise level.

Anechoic target detection was determined by the computerised image analysis program by drawing a region-of-interest around the array of anechoic targets and calculating the correlation coefficient between the detected target and an ideal target using a matched filter. The correlation coefficient, $\mathrm{R}$, was then transformed into the Z-coefficient, which is the normal distribution of the correlation coefficient calculated as follows (Altman 1991):

$Z$ coefficient $=(1 / 2) \ln [(1+R) /(1-R)]$.

The uncertainty $(95 \% \mathrm{CI})$ in the anechoic target detection measurement due to reanalysis using the USQA program was $\pm 1 \%$; this represents the uncertainty in comparison between different imaging modes with the probe clamped. 
Contrast Resolution This describes the scanner's contrast dynamic range and gives an indication of the low and high contrast detectabilities. The ability of a scanner to display a low contrast or a high contrast lesion in a tissue background is limited by the noise or the saturation point of the scanner, respectively, and, as such, the contrast resolution of a scanner may be representative of dynamic range gradient. Contrast resolution can be evaluated by imaging cylinders with different scattering levels from the surrounding material, which are present in most test objects.

Contrast resolution was measured using the prototype computerised image analysis program by placing two points at opposite positions on the contrast target's imaged circumference. The program then drew two circles, one within the target and the other outside the target. The contrast resolution of each of the targets was determined by calculating the ratio of the mean pixel intensity of the target $\left(\mathrm{M}_{\mathrm{in}}\right)$ and the mean pixel intensity of the background $\left(\mathrm{M}_{\text {out }}\right)$ :

Contrast Resolution $=\left(\mathrm{M}_{\mathrm{in}} / \mathrm{M}_{\text {out }}\right)$.

The uncertainty $(95 \% \mathrm{CI})$ in the visibility index measurement due to reanalysis using the USQA program was $\pm 3 \%$; this represents the uncertainty in comparison between different imaging modes with the probe clamped.

Furthermore, this procedure was used to determine which of the three different types of fat-mimicking layer best replicated the effect produced by the fat layer. The effect of the three different types of fat-mimicking layers on the image quality parameters was investigated, in order to identify a suitable fat-mimicking layer for performance and quality control testing. The temperature of the test phantoms and the fat-mimicking layers was maintained at $22^{\circ} \mathrm{C} \pm 2{ }^{\circ} \mathrm{C}$ (room temperature, normal testing conditions) during testing of the two ultrasound scanners and their respective transducers. The 
two ultrasound scanners and their respective transducers were evaluated using three different test phantom combination, as follows: test phantom and $1 \mathrm{~cm}$ olive oil layer; test phantom and $1 \mathrm{~cm}$ lard layer; and test phantom and $1 \mathrm{~cm}$ lard layer embedded with fish oil capsules $(<1 \mathrm{~mm})$. The olive oil was poured into the imaging wells of the test phantoms, while the lard layers were coupled to the test phantoms using ultrasonic jelly. The image qualities of the two ultrasound scanners' curvilinear abdominal transducers were evaluated using the three test phantom combinations described above, using the same procedure as that previously outlined for the subcutaneous pig fat layer. 


\section{RESULTS}

\section{Anechoic Target Detection}

Results regarding anechoic target detection of the $2 \mathrm{D}$ conventional imaging and THI mode of the 4C1 and C5-2 transducers for the $6 \mathrm{~mm}, 4 \mathrm{~mm}$ and $2 \mathrm{~mm}$ targets at depths of $30 \mathrm{~mm}, 80 \mathrm{~mm}$ and $130 \mathrm{~mm}$ using the subcutaneous pig fat layer, olive oil, lard and lard with fish oil capsules fat-mimicking layers are presented in Tables $1 \mathrm{a}-1 \mathrm{c}$ respectively.

Subcutaneous Pig Fat Layer. For the most part, there was an improvement in anechoic target detection performance with THI compared with 2D conventional imaging, when the subcutaneous pig fat layer was used.

Olive Oil Fat-Mimicking Layer. In general, the anechoic target detection performance with THI was similar to or better than the anechoic target detection performance of 2D conventional imaging, when the olive oil fat-mimicking layer was used.

\section{Lard Fat-Mimicking Layer}

In general the anechoic target detection performance with THI was similar or slightly worse than the anechoic target detection performance of 2D conventional imaging, when the lard fat-mimicking layer was used.

Lard and Fish Oil Capsule Fat-Mimicking Layer. In general, the anechoic target detection performance with THI was similar to or slightly worse than that of the anechoic target detection performance of 2D conventional imaging, when the lard and fish oil capsule fat-mimicking layer was used. 


\section{Contrast resolution}

The contrast resolution results of the $2 \mathrm{D}$ conventional imaging and THI mode of the 4C1 and C5-2 transducers for the different grey-scale targets using the subcutaneous pig fat layer, the olive oil, lard and lard with fish oil capsules fat-mimicking layers are presented in Figs. $2 \mathrm{a}-2 \mathrm{~d}$, respectively.

Subcutaneous Pig Fat Layer, Olive Oil, Lard and Lard and Fish Oil Capsule Fat-Mimicking Layers. For the most part, there was no significant difference in contrast resolution performance with THI compared with 2D conventional imaging, when the subcutaneous pig fat layer and the three fat-mimicking layers were used. 


\section{DISCUSSION}

The effect of subcutaneous pig fat on the image quality parameters anechoic target detection and contrast resolution performance for the $2 \mathrm{D}$ conventional imaging and the THI modes of the Aspen and the HDI 5000 ultrasound scanners was investigated. The subcutaneous pig fat layer was used to replicate, as closely as possible, the clinical situation and thus attempt to reproduce anechoic target detection and contrast resolution improvements in image quality reported clinically with the use of THI (Puls et al 2000; Shapiro et al 1998; Tanaka et al 2000; Tranquart et al 1999). The layer of subcutaneous pig fat was used to induce phase aberrations and beam distortion, in order to determine whether THI reduces the effect of beam distortion and image clutter as a result of the harmonic echoes passing only once (at echo reception) through the subcutaneous fat layer; this would be due to the majority of the harmonic echoes originating within the tissue-mimicking phantom, deep to the subcutaneous fat layer. Indeed, improvements in the anechoic target detection performance were reproduced using this method, which may be attributed to both the narrower second harmonic beam width and the reduction in clutter. However, no improvements where found, when using THI, for contrast resolution. This result was unexpected, as many clinical studies in the literature have reported that THI improves contrast resolution across a wide range of clinical applications (Puls et al 2000; Shapiro et al 1998; Tanaka et al 2000; Tranquart et al 1999). Indeed, similar results were obtained with the tissuemimicking material phantom without using the subcutaneous pig fat layer in the previous study (Browne et al 2004), which suggests that the image quality improvements attributed to THI do not appear to be dependent on the presence of phase aberrations or beam distortion, which are invariably generated in in-vivo 
conditions. The $2 \mathrm{~mm}$ anechoic target detection result for conventional B-mode imaging of the Aspen 4C1 transducer with the subcutaneous fat layer was found to be $\mathrm{Z}=0.65$ at a depth of $80 \mathrm{~mm}$, while the larger targets $4 \mathrm{~mm}$ and $6 \mathrm{~mm}$ at $80 \mathrm{~mm}$ were not detected for conventional B-mode imaging of the Aspen 4C1 transducer. This is a surprising result, as it would be expected that the larger targets would be easier to detect compared with the smaller targets: this odd result may be due to the computer algorithm detecting a speckle pattern in the image. The authors are currently investigating the difference in detectability of the different size targets for human observers and the computer analysis program. This lack of improvement in contrast resolution performance with THI may be may be due to a combination of two factors, the backscatter values of the targets embedded in the test phantom and the lack of contrast targets of varying size at a range of depths within the test phantom. This latter factor would facilitate the measurement of the contrast-detail performance of the ultrasound scanner (Hall et al 1993; Lopez et al 1987; Lopez et al 1992). M Cormack $^{\mathrm{c}}$ et al 2002 detected improvements in contrast resolution with THI for a range of ultrasound scanners using a prototype test phantom which had sets of conical targets of varying backscatter at a range of depths. The contrast-detail analysis results obtained in this study were found to have a good correlation with clinical perception of contrast resolution for the same ultrasound scanners (McCormack et al 2002). This result suggests that a new approach to evaluating contrast resolution may need to be investigated. Furthermore, the use of the current design of tissue-mimicking phantom in combination with a fat layer was possibly not appropriate for the evaluation of the contrast enhancements attributed to THI 
It was felt that the use of fat-mimicking layers used in combination with the test phantom would also better demonstrate the clinical improvements reported in the literature arising from the use of THI on the two different ultrasound scanners, similar to that found for the subcutaneous pig fat layer, and, consequently, better demonstrate the clinical improvements reported in the literature arising from the use of THI (Entrekin et al 2001; Tanaka et al 2000; Tranquart et al 1999). This technique could also be used to quantify improvements in image quality of new imaging modes with ultrasound scanners of varying complexity. Only the magnitude of the visibility index differs between the fat-mimicking layers and the subcutaneous pig fat layer. In the present study, the three different fat-mimicking layers were found to produce similar results to those obtained using the subcutaneous fat layer. The attenuations of the different fat layers were quiet different (the subcutaneous fat layer $=3 \mathrm{~dB} \mathrm{~cm}^{-1}$ at 2 $\mathrm{MHz}$, olive oil layer $=0.87 \mathrm{~dB} \mathrm{~cm}^{-1}$ at $3 \mathrm{MHz}$ and the lard layers $=12.6 \mathrm{~dB} \mathrm{~cm}^{-1}$ at 3 $\mathrm{MHz}$ ); this would have had an effect on the magnitude of harmonics generated and, therefore, on the comparative results obtained in the study. However, this effect may not have been a major one, as improvements were found for anechoic target detection with THI compared with conventional B-mode imaging for all four fat layers used in the study. Clinically-reported improvement in anechoic target detection using THI was confirmed in our experiments with the three different types of fat-mimicking layers; furthermore, as can be seen from Tables $1 \mathrm{a}-1 \mathrm{c}$, no improvements in anechoic target detection were seen with THI for the phantom alone. Therefore, the fat-mimicking layers may be useful for evaluating anechoic target detection image quality performance of THI compared with 2D conventional imaging. However, the reported improvement in contrast resolution was not observed in our study. Furthermore, different-sized fat layers were initially used in this study, but it was found that fat layers 
larger than $1 \mathrm{~cm}$ are very attenuating and images of the anechoic targets at depths greater than $3 \mathrm{~cm}$ could not be obtained, nor could images of the contrast targets be obtained. 


\section{CONCLUSIONS}

In this paper, it was found that THI improved anechoic target detection performance with the use of a subcutaneous pig fat layer compared with $2 \mathrm{D}$ conventional imaging and that a similar trend in the results was found for three different types of fatmimicking layers evaluated; only the magnitude differed. However, THI was not found to improve contrast resolution with any of the different fat-layers. This might be due to the particular backscattering properties of the targets relative to those of the surrounding medium and to the particular method used to determine the contrast resolution (only four different backscattering targets at one set depth). Therefore, it was felt that the lack of improvement in contrast resolution performance might be due to the test phantom design and not to whether a layer was present that caused beam distortion and phase aberrations. It was also found that the use of fat-mimicking layers replicated the effect of a subcutaneous pig fat layer on the image quality parameters anechoic target detection and contrast resolution and may, therefore, be useful for evaluating the image quality performance of THI compared with $2 \mathrm{D}$ conventional imaging. 


\section{REFERENCES}

Averkiou MA, Roundhill DN, and Powers JE. A new imaging technique based on the nonlinear properties of tissues. IEEE Ultrasonics Symposium. 1997;1561-1566.

Browne JE, Ramnarine KV, Watson AJ, and Hoskins PR. Assessment of the Acoustic Properties of Common Tissue-Mimicking Test Phantoms. Ultrasound in Medicine and Biology. 2003;29:1053-1060.

Browne JE, Watson AJ, Gibson NM, Dudley NJ, and Elliott AT. Objective Measurements of Image Quality. Ultrasound in Medicine and Biology. 2004;30:229237.

Christopher T. Finite amplitude distortion-based inhomogeneous pulse echo ultrasonic imaging. Ieee Transactions on Ultrasonics Ferroelectrics and Frequency Control. 1997;44:125-139.

Claudon M, Tranquart F, Evans DH, Lefevre F, and Correas JM. Advances in ultrasound. European Radiology. 2002;12:7-18.

Desser TS and Jeffrey RB. Tissue harmonic imaging techniques: Physical principles and clinical applications. Seminars in Ultrasound Ct and Mri. 2001;22:1-10.

Entrekin RR, Porter BA, Sillesen HH, Wong AD, Cooperberg PL, and Fix CH. Realtime spatial compound imaging: Application to breast, vascular, and musculoskeletal ultrasound. Seminars in Ultrasound Ct and Mri. 2001;22:50-64. 
Gammell RM, Le Croisette DH, and Heyser RC. Temperature and frequency dependence of ultrasonic attenuation in selected tissues. Ultrasound in Medicine and Biology. 1979;5:269-277.

Gibson NM, Dudley NJ, and Griffith K. A computerised quality control testing system for B-mode ultrasound. Ultrasound in Medicine and Biology. 2001;27:1697-1711.

Hall TJ, Insana MF, Soller NM, and Harrison LA. Ultrasound Contrast-Detail Analysis - A Preliminary-Study in Human Observer Performance. Medical Physics. $1993 ; 20: 117-127$.

Lewin PA and Busk H. In vivo ultrasonic measurements of tissue properties. IEEE Ultrasonics Symposium. 1982;709-712.

Li YD and Zagzebski JA. Computer model for harmonic ultrasound imaging. IEEE Transactions on Ultrasonics Ferroelectrics and Frequency Control. 2000;47:10001013.

Lopez H, Loew MH, Butler PF, and Hill MH. A Clinical-Evaluation of Contrast-Detail Analysis of Ultrasound Images. Ultrasonic Imaging. 1987;9:49-50.

Lopez H, Loew MH, and Goodenough DJ. Objective Analysis of Ultrasound Images by Use of A Computational Observer. Ieee Transactions on Medical Imaging. 1992;11:496-506. 
McCormack S, Evans JA, and Metcalfe SC. Assessing the improvement in contrast detail resolution using tissue harmonic imaging. Ultrasound Quality Assurance 2002: B-mode, Doppler and New Modalities.

Puls I, Berg D, Maurer M, Schliesser M, Hetzel G, and Becker G. Transcranial sonography of the brain parenchyma: Comparison of B-mode imaging and tissue harmonic imaging. Ultrasound in Medicine and Biology. 2000;26:189-194.

Shapiro RS, Wagreich J, Parsons RB, Stancato-Pasik A, Yeh HC, and Lao R. Tissue harmonic imaging sonography: Evaluation of image quality compared with conventional sonography. American Journal of Roentgenology. 1998;171:1203-1206.

Tanaka S, Oshikawa O, Sasaki T, Ioka T, and Tsukuma H. Evaluation of tissue harmonic imaging for the diagnosis of focal liver lesions. Ultrasound in Medicine and Biology. 2000;26:183-187.

Tranquart F, Grenier N, Eder V, and Pourcelot L. Clinical use of ultrasound tissue harmonic imaging. Ultrasound in Medicine and Biology. 1999;25:889-894.

Ward B, Baker AC, and Humphrey VF. Nonlinear propagation applied to the improvement of resolution in diagnostic medical ultrasound. Journal of the Acoustical Society of America. 1997;101:143-154. 
Table 1a. Z-coefficient of the $6 \mathrm{~mm}$ anechoic target as a function of depth for 2D conventional imaging and $\mathrm{THI}$ of the $4 \mathrm{C} 1$ and $\mathrm{C5}-2$ curvilinear abdominal transducers in the general purpose test object with the subcutaneous pig fat layer, the olive oil, the lard and the lard and fish oil capsules fat-mimicking layers.

\begin{tabular}{|c|c|c|c|c|}
\hline $\begin{array}{c}\text { Type of layer } \\
\text { Depth of anechoic } \\
\text { target }\end{array}$ & $\begin{array}{r}\mathrm{4C1} \\
\text { 2D imaging } \\
\text { Focal points } \\
150 \\
\text { Error } \\
\end{array}$ & $\begin{array}{r}\text { 4C1 } \\
\text { THI } \\
110 \text { and } \\
1) \\
\end{array}$ & $\begin{array}{c}\text { C5-2 } \\
\text { 2D imaging } \\
\text { Focal points } \\
\text { and } 1 \\
\text { Error } \\
\end{array}$ & $\begin{array}{l}\text { C5-2 } \\
\text { THI } \\
\\
\text { m } 50,90 \\
1) \\
\end{array}$ \\
\hline $\begin{array}{c}\text { Subcutaneous fat } \\
30 \mathrm{~mm} \\
80 \mathrm{~mm} \\
140 \mathrm{~mm}\end{array}$ & $\begin{array}{c}0.81 \\
0 \\
0\end{array}$ & $\begin{array}{c}0.92 \\
0.58 \\
0\end{array}$ & $\begin{array}{c}0.96 \\
0.8 \\
0\end{array}$ & $\begin{array}{c}1.03 \\
1.0 \\
0\end{array}$ \\
\hline $\begin{array}{c}\text { Olive oil } \\
30 \mathrm{~mm} \\
80 \mathrm{~mm} \\
140 \mathrm{~mm} \\
\end{array}$ & $\begin{array}{c}0.99 \\
0.87 \\
0 \\
\end{array}$ & $\begin{array}{c}0.86 \\
0.84 \\
0 \\
\end{array}$ & $\begin{array}{c}0.98 \\
0.75 \\
0 \\
\end{array}$ & $\begin{array}{c}1.05 \\
0.83 \\
0 \\
\end{array}$ \\
\hline $\begin{array}{c}\text { Lard } \\
30 \mathrm{~mm} \\
80 \mathrm{~mm} \\
140 \mathrm{~mm} \\
\end{array}$ & $\begin{array}{c}1.09 \\
1.08 \\
0 \\
\end{array}$ & $\begin{array}{c}1.01 \\
1.02 \\
0 \\
\end{array}$ & $\begin{array}{c}1.12 \\
0.89 \\
0 \\
\end{array}$ & $\begin{array}{c}1.14 \\
0.66 \\
0 \\
\end{array}$ \\
\hline $\begin{array}{c}\text { Lard and fish oil } \\
\text { capsules } \\
30 \mathrm{~mm} \\
80 \mathrm{~mm} \\
140 \mathrm{~mm} \\
\end{array}$ & $\begin{array}{c}0.96 \\
0.83 \\
0 \\
\end{array}$ & $\begin{array}{c}0.89 \\
0.69 \\
0 \\
\end{array}$ & $\begin{array}{c}0.68 \\
0.85 \\
0 \\
\end{array}$ & $\begin{array}{c}1.0 \\
0.82 \\
0 \\
\end{array}$ \\
\hline $\begin{array}{c}\text { Phantom alone } \\
\begin{array}{c}30 \mathrm{~mm} \\
80 \mathrm{~mm} \\
140 \mathrm{~mm}\end{array}\end{array}$ & $\begin{array}{l}1.14 \\
0.89 \\
0.71\end{array}$ & $\begin{array}{l}0.87 \\
0.94 \\
0.57\end{array}$ & $\begin{array}{l}1.09 \\
0.97 \\
0.72\end{array}$ & $\begin{array}{c}0.79 \\
0.73 \\
0\end{array}$ \\
\hline
\end{tabular}


Table 1b. Z-coefficient of the $4 \mathbf{~ m m}$ anechoic target as a function of depth for $\mathbf{2 D}$ conventional imaging and THI of the $4 \mathrm{C} 1$ and $\mathrm{C5}-2$ curvilinear abdominal transducers in the general purpose test object with the subcutaneous pig fat layer, the olive oil, the lard and the lard and fish oil capsules fat-mimicking layers.

\begin{tabular}{|c|c|c|c|c|}
\hline $\begin{array}{c}\text { Type of layer } \\
\text { Depth of anechoic } \\
\text { target }\end{array}$ & $\begin{array}{r}\text { 4C1 } \\
\text { 2D imaging } \\
\text { Focal points } \\
15 \\
\text { Error } \\
\end{array}$ & $\begin{array}{l}\text { 4C1 } \\
\text { THI } \\
110 \text { and } \\
1) \\
\end{array}$ & $\begin{array}{r}\text { C5-2 } \\
\text { 2D imaging } \\
\text { Focal points } \\
\text { and } 1 \\
\text { Error } \\
\end{array}$ & $\begin{array}{l}\text { C5-2 } \\
\text { THI } \\
, 50,90 \\
1) \\
\end{array}$ \\
\hline $\begin{array}{c}\text { Subcutaneous fat } \\
30 \mathrm{~mm} \\
80 \mathrm{~mm} \\
140 \mathrm{~mm}\end{array}$ & $\begin{array}{c}0.68 \\
0 \\
0\end{array}$ & $\begin{array}{c}0.68 \\
0.71 \\
0\end{array}$ & $\begin{array}{c}0.98 \\
0.83 \\
0\end{array}$ & $\begin{array}{c}1.1 \\
0.93 \\
0\end{array}$ \\
\hline $\begin{array}{c}\text { Olive oil } \\
30 \mathrm{~mm} \\
80 \mathrm{~mm} \\
140 \mathrm{~mm} \\
\end{array}$ & $\begin{array}{c}0.78 \\
0.77 \\
0 \\
\end{array}$ & $\begin{array}{c}0.75 \\
0.85 \\
0 \\
\end{array}$ & $\begin{array}{c}0.81 \\
0.51 \\
0 \\
\end{array}$ & $\begin{array}{c}0.94 \\
0.89 \\
0 \\
\end{array}$ \\
\hline $\begin{array}{c}\text { Lard } \\
30 \mathrm{~mm} \\
80 \mathrm{~mm} \\
140 \mathrm{~mm} \\
\end{array}$ & $\begin{array}{c}0.96 \\
1.07 \\
0 \\
\end{array}$ & $\begin{array}{c}1.02 \\
0.99 \\
0 \\
\end{array}$ & $\begin{array}{c}1.06 \\
0.79 \\
0 \\
\end{array}$ & $\begin{array}{c}0.99 \\
0.79 \\
0 \\
\end{array}$ \\
\hline $\begin{array}{c}\text { Lard and fish oil } \\
\text { capsules } \\
30 \mathrm{~mm} \\
80 \mathrm{~mm} \\
140 \mathrm{~mm}\end{array}$ & $\begin{array}{c}0.85 \\
0.82 \\
0\end{array}$ & $\begin{array}{c}0.77 \\
0.71 \\
0\end{array}$ & $\begin{array}{c}0.98 \\
0.79 \\
0\end{array}$ & $\begin{array}{c}1.13 \\
0.82 \\
0\end{array}$ \\
\hline $\begin{array}{c}\text { Phantom alone } \\
30 \mathrm{~mm} \\
80 \mathrm{~mm} \\
140 \mathrm{~mm} \\
\end{array}$ & $\begin{array}{l}1.01 \\
0.78 \\
0.68 \\
\end{array}$ & $\begin{array}{c}0.79 \\
0.87 \\
0 \\
\end{array}$ & $\begin{array}{c}1.06 \\
0.81 \\
0 \\
\end{array}$ & $\begin{array}{c}0.81 \\
0.71 \\
0 \\
\end{array}$ \\
\hline
\end{tabular}


Table 1c. Z-coefficient of the $\mathbf{2} \mathbf{~ m m}$ anechoic target as a function of depth for $\mathbf{2 D}$ conventional imaging and $\mathrm{THI}$ of the $4 \mathrm{C} 1$ and $\mathrm{C5}-2$ curvilinear abdominal transducers in the general purpose test object with the subcutaneous pig fat layer, the olive oil, the lard and the lard and fish oil capsules fat-mimicking layers.

\begin{tabular}{|c|c|c|c|c|}
\hline $\begin{array}{c}\text { Type of layer } \\
\text { Depth of anechoic } \\
\text { target }\end{array}$ & $\begin{array}{r}\text { 4C1 } \\
\text { 2D imaging } \\
\text { Focal points } \\
150 \\
\text { Error } \\
\end{array}$ & $\begin{array}{l}\text { 4C1 } \\
\text { THI } \\
110 \text { and } \\
1) \\
\end{array}$ & $\begin{array}{r}\text { C5-2 } \\
\text { 2D imaging } \\
\text { Focal points } \\
\text { and } 1 \\
\text { Error } \\
\end{array}$ & $\begin{array}{l}\text { C5-2 } \\
\text { THI } \\
, 50,90 \\
1) \\
\end{array}$ \\
\hline $\begin{array}{c}\text { Subcutaneous fat } \\
30 \mathrm{~mm} \\
80 \mathrm{~mm} \\
140 \mathrm{~mm} \\
\end{array}$ & $\begin{array}{c}0.94 \\
0.65 \\
0 \\
\end{array}$ & $\begin{array}{c}0.59 \\
0.67 \\
0 \\
\end{array}$ & $\begin{array}{c}0.67 \\
0.69 \\
0 \\
\end{array}$ & $\begin{array}{c}0.8 \\
0.75 \\
0 \\
\end{array}$ \\
\hline $\begin{array}{c}\text { Olive oil } \\
30 \mathrm{~mm} \\
80 \mathrm{~mm} \\
140 \mathrm{~mm} \\
\end{array}$ & $\begin{array}{l}0 \\
0 \\
0 \\
\end{array}$ & $\begin{array}{l}0 \\
0 \\
0 \\
\end{array}$ & $\begin{array}{l}0 \\
0 \\
0 \\
\end{array}$ & $\begin{array}{c}0.54 \\
0.61 \\
0 \\
\end{array}$ \\
\hline $\begin{array}{c}\text { Lard } \\
30 \mathrm{~mm} \\
80 \mathrm{~mm} \\
140 \mathrm{~mm} \\
\end{array}$ & $\begin{array}{c}0.79 \\
1.02 \\
0 \\
\end{array}$ & $\begin{array}{c}0.7 \\
0.86 \\
0 \\
\end{array}$ & $\begin{array}{c}0.73 \\
0 \\
0 \\
\end{array}$ & $\begin{array}{c}0.91 \\
0 \\
0 \\
\end{array}$ \\
\hline $\begin{array}{c}\text { Lard and fish oil } \\
\text { capsules } \\
30 \mathrm{~mm} \\
80 \mathrm{~mm} \\
140 \mathrm{~mm}\end{array}$ & $\begin{array}{c}0.83 \\
0 \\
0\end{array}$ & $\begin{array}{c}1.22 \\
0 \\
0\end{array}$ & $\begin{array}{l}0 \\
0 \\
0\end{array}$ & $\begin{array}{l}0 \\
0 \\
0\end{array}$ \\
\hline $\begin{array}{c}\text { Phantom alone } \\
30 \mathrm{~mm} \\
80 \mathrm{~mm} \\
140 \mathrm{~mm}\end{array}$ & $\begin{array}{c}0.57 \\
0.55 \\
0 \\
\end{array}$ & $\begin{array}{l}0 \\
0 \\
0\end{array}$ & $\begin{array}{c}0.67 \\
0.74 \\
0 \\
\end{array}$ & $\begin{array}{c}0.5 \\
0.57 \\
0 \\
\end{array}$ \\
\hline
\end{tabular}


Fig. 1. (a) The RMI 403 GS LE multipurpose grey-scale phantom; (b) Anechoic target group: RMI 403 GS LE test object; (c) Contrast target group: RMI 403 GS LE test object.

Fig. 2. Contrast resolution of the B-mode (-B) and THI (-T) mode of the $4 C 1$ and C5-2 transducers. (a) Model 403GS LE test phantom and pig fat layer; (b) Model 403GS LE test phantom and olive oil layer; (c) Model 403GS LE test phantom and lard layer;(c) Model 403GS LE test phantom and lard \& fish oil capsules layer.

Fig. 3. 2D conventional images of the anechoic targets using the 4C1 transducer. (a) Subcutaneous pig fat layer; (b) Olive oil fat-mimicking layer; (c) Lard fat-mimicking layer and (d) Lard and fish oil capsules fa-mimicking layer. 


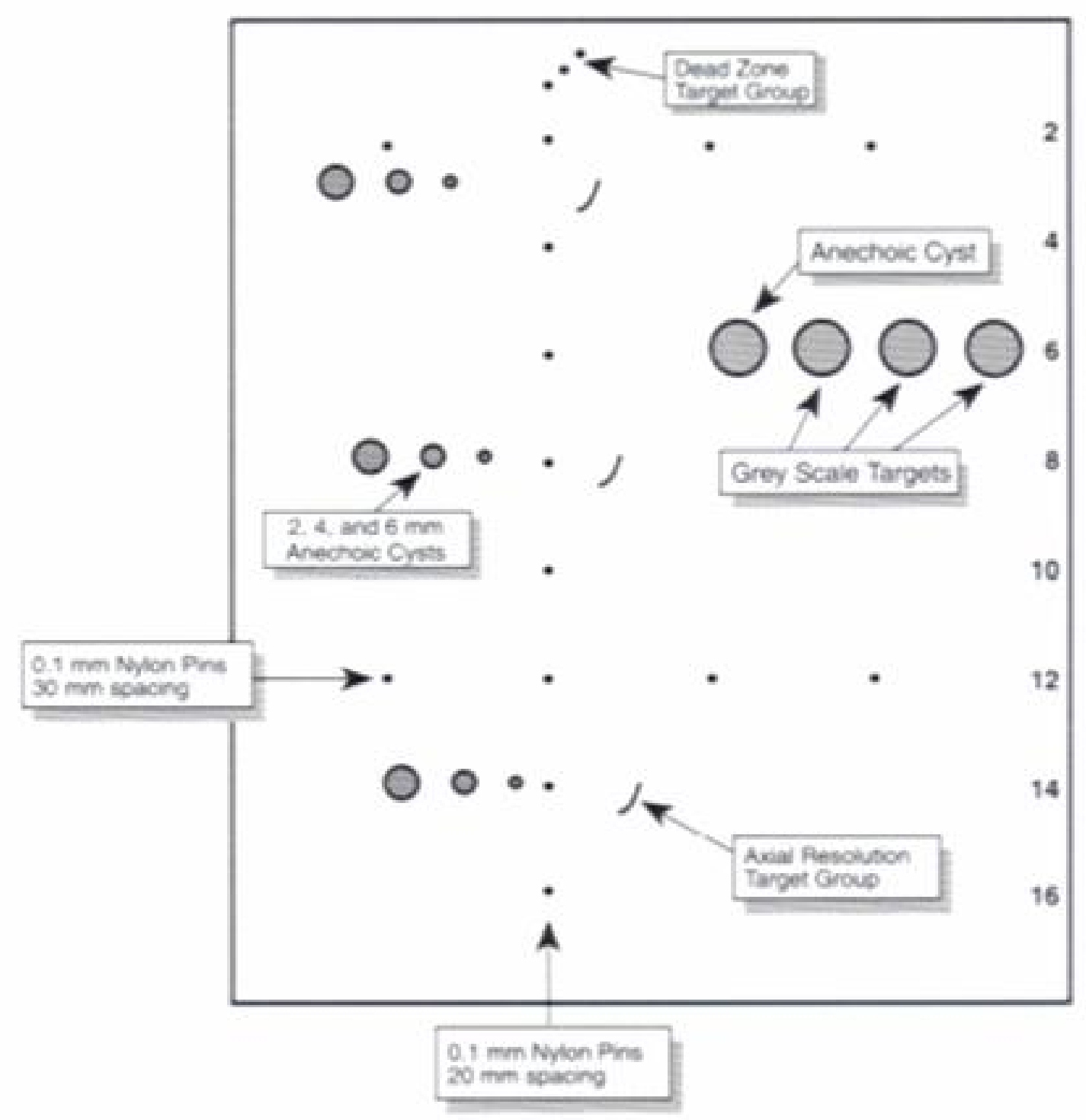

Fig. 1(a) 


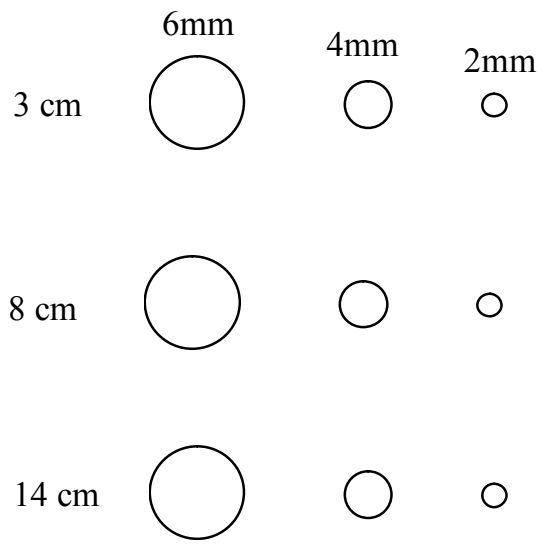

Fig. 1(b) 
Fig. 1(c)

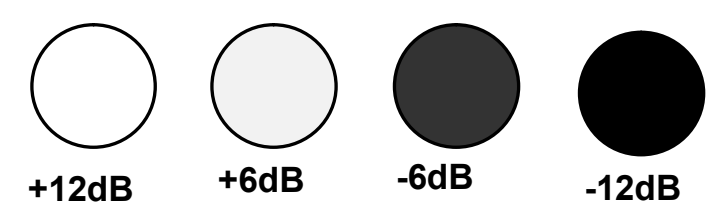




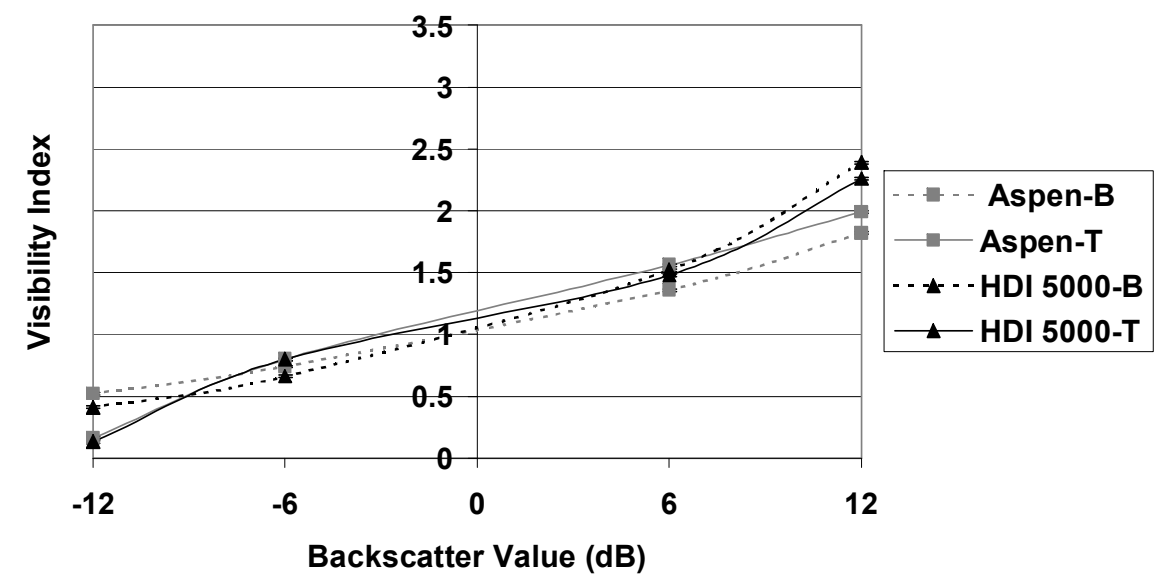

Fig. 2(a) 


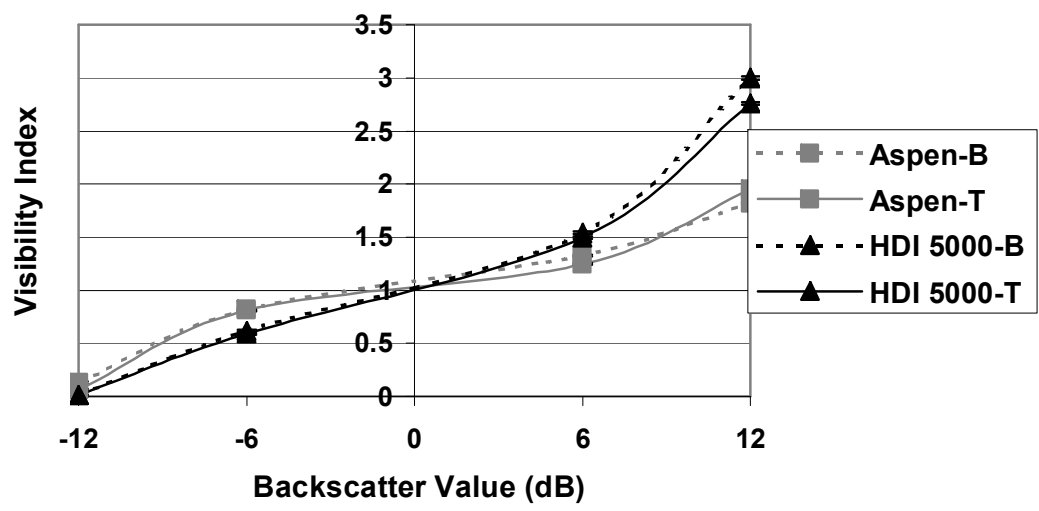

Fig. 2(b) 


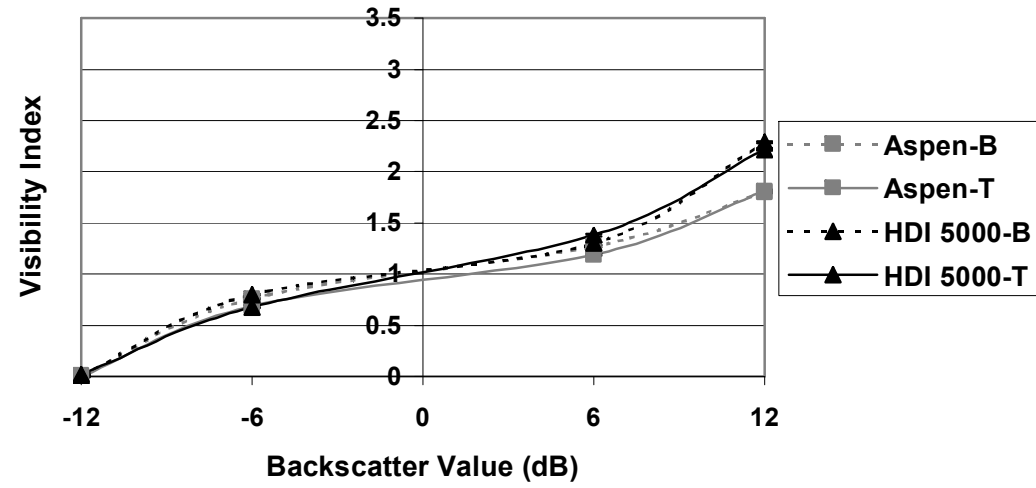

Fig. 2(c) 


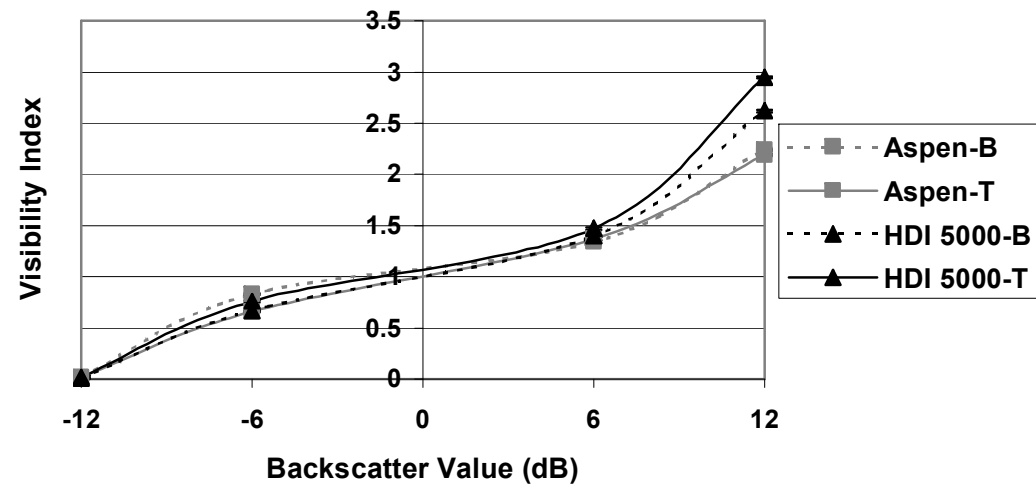

Fig. 2(d) 


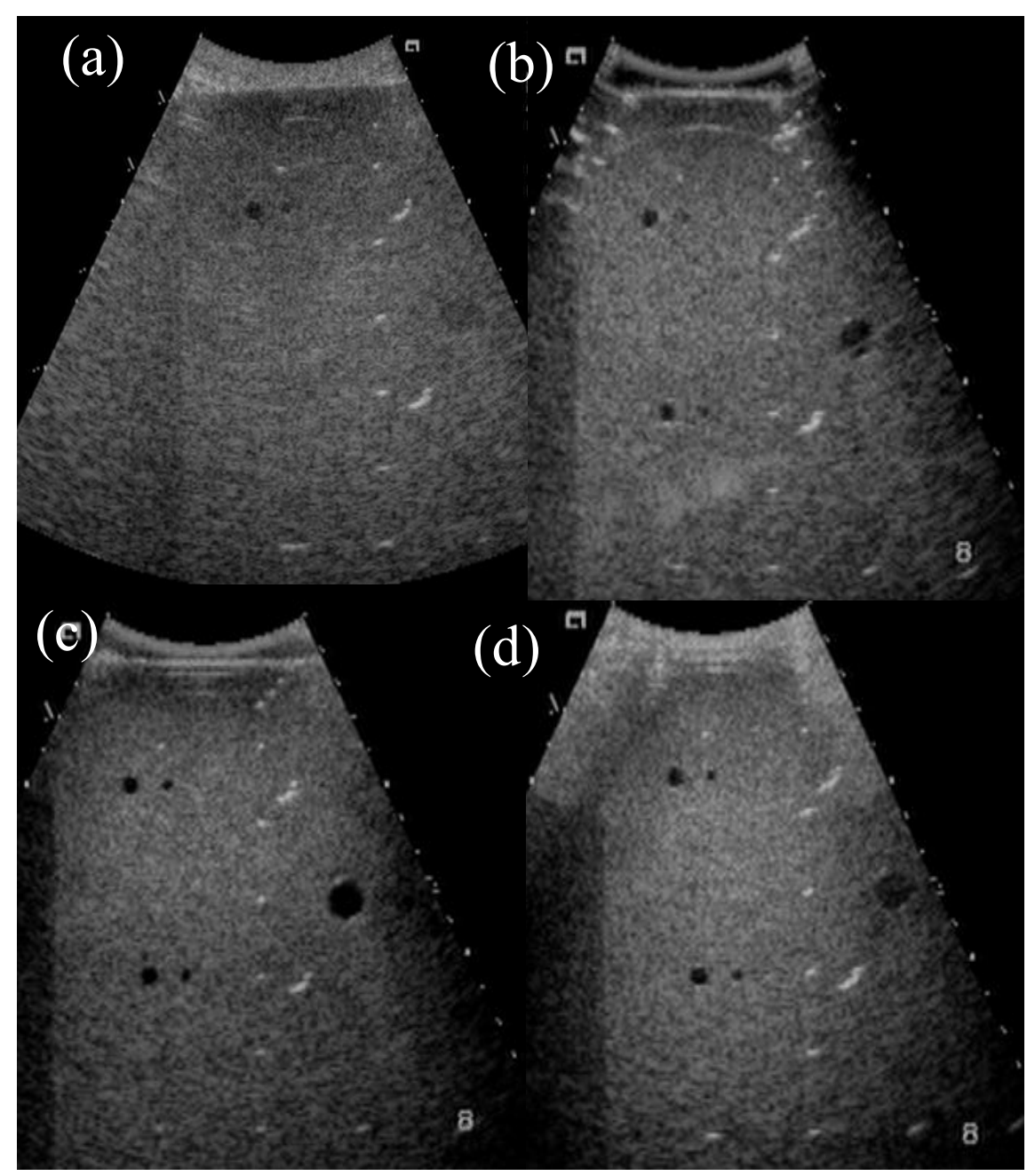

Fig. 3 